\title{
UMA CONTRIBUIÇÃo À DOGMÁTICA DOS DELITOS DE PERIGO
}

\author{
ABSTRATO
}

\author{
Marco Antonio Santos Reis ${ }^{1}$
}

\begin{abstract}
According to the dominant criminal law's dogmatic the so called „risk crimes“ can be divided into crimes of abstract and concrete risk. Abstract crimes describes a typical behaviour which usually lead to injury or a situation of concrete danger. Such crimes exist when the legislator neither specifies injury nor a concrete danger as a standard on legal rules. The present work investigates three main aspects of this type of crimes: their contents, their legal structure and their legitimacy.
\end{abstract}

Keywords: Abstrakte risk - Result - Unjust - Risk

\section{Zusammenfassung}

Nach der herrschenden Dogmatik werden die Gefährdungsdelikte in abstrakte und konkrete eingeteilt. Abstrakte Gefährdungsdelikte beschreiben ein typischerweise gefährliches Verhalten. Diese Delikte sollen dann vorliegen, wenn der Gesetzgeber weder eine Verletzung noch eine konkrete Gefährdung des durch die Norm geschützen Rechsguts als tatbestandlichen Ergolg vorgesehen hat. Die vorliegende Arbeit untersucht drei aspekte des abstrakte Gefährdungsdelikte: seinen Inhalt, seine Struktur und sein Legitimation.

Stichwörter: abstrakte Gefährdung - Erfolg - Unrecht - Risiko

\section{Resumo}

De acordo com a dogmática dominante, os delitos de perigo são divididos em delitos de perigo abstrato e concreto. Os delitos abstratos descrevem uma conduta típica ou geralmente perigosa. Estes delitos devem existir, pois, quando o legislador não determina nem uma lesão e tampouco uma colocação concreta em perigo de um bem jurídico protegido pela norma. O presente trabalho investiga três aspectos dos delitos de perigo abstrato: seu conteúdo, sua estrutura e sua legitimação.

Palavras-chave: perigo abstrato - resultado - injusto - risco

\section{Plano de Investigação}

O debate a respeito dos delitos de perigo abstrato não é uma novidade para a literatura jurídico-penal. Apesar disso, a atenção dispensada a esta figura pela doutrina brasileira é relativamente recente ${ }^{2}$. O interesse pelo tema se justifica não só em virtude de seu relevo social, mas, sobretudo, devido à larga e recente produção legislativa neste sentido.

\footnotetext{
${ }^{1}$ Advogado e mestrando em Direito Penal pela Universidade do Estado do Rio de Janeiro (UERJ).

${ }^{2}$ Cite-se: BOTTINI, Pierpaolo Cruz. Crimes de perigo abstrato e princípio da precaução na sociedade de risco. São Paulo: Revista dos Tribunais, 2007.
} 
Entretanto, se por um lado o interesse jurídico a respeito dos crimes de perigo abstrato se intensifica no cenário brasileiro, por outro, pouco foram vistas as questões fundamentais deste tipo de delito por nossa doutrina que, em geral, é vacilante quanto ao que se deve entender por perigo abstrato e, predominantemente, rejeita-o como tipo de delito legítimo.

O presente estudo tem por escopo abordar tais questões em um desenvolvimento trifásico. Em um primeiro bloco, o artigo ocupar-se-á da apresentação dos principais contributos sobre o instituto sob exame. Neste sentido, caberá ao escrito esclarecer o que a doutrina, costumeiramente, entende por perigo abstrato: seu conceito, a sua estrutura e os fundamentos comumente oferecidos pela doutrina.

Em um segundo bloco, o estudo apresenta e responde as objeções levantadas por parte da doutrina contra a dogmática dos crimes de perigo abstrato.

Por fim, o escrito realiza algumas considerações sobre a orientação que considera mais acertada no que diz respeito ao fundamento e à dogmática dos referidos delitos.

2. O delito de perigo abstrato: aspectos dogmáticos

2.1 Um primeiro esclarecimento: o perigo abstrato e os crimes de resultado

O primeiro problema dos delitos de perigo abstrato é, sem dúvidas, determinar se, afinal, são delitos de resultado ou de mera atividade. É lógica ou terminologicamente possível a existência de um perigo abstrato? Trata-se, pois, de um resultado ou de uma mera violação?

Para um setor específico da doutrina é inviável o uso do termo "perigo abstrato". O perigo é sempre perigo concreto, isto é, um perigo concebido empírica e objetivamente sob a forma de probabilidade ou possibilidade de uma lesão a bens jurídicos ${ }^{3}$, concepção esta que guarda estreita conexão com a classificação dos delitos em crimes de resultado e de mera atividade.

Os delitos de perigo abstrato são, portanto, segundo a clássica divisão, sem sombra de dúvidas, delitos de mera conduta ou de mera atividade (schlichte Tätigkeitsdelikte) ${ }^{4}$.

\footnotetext{
${ }^{3}$ Entre os que rejeitam a existência de perigo abstrato: BOHNERT, Joachim. Die Abstraktheit der abstrakten Gefährdungsdelikte. In: JuS, 1984, p. 183; PÜTZ, Willy.Gefahrbegriff im Strafrecht. Dissertation Köln: 1936, p. 36; KÖHLER, Michael. Strafrecht. Allgemeiner Teil. Berlin;Heidelberg: Springer, 1997, p. 23, para quem o perigo abstrato é uma "mera violação da ordem (bloße Ordnungsverstöße).

${ }^{4}$ Como referências não exaustivas: BOCKELMANN/VOLK. Strafrecht Allgemeiner Teil. 4.Auflage. C.H. Beck: München, 1987, §19, p.151; GRAUL, Eva. Abstrakte Gefährdungsdelikte und Präsumtionen im
} 
Esta antiga classificação que atribuía ao perigo abstrato a condição de crime de mera atividade vem sendo, contudo, modificada. Neste sentido, afirma Wohlers que "os delitos de perigo abstrato podem tanto ser delitos de atividade como também delitos de resultado, em sentido formal" (Abstrakte Gefährdungsdelikte können sowohl Tätigkeits- als auch Erfolgsdelikte (im formellen Sinne) sein") ${ }^{5}$.

Hoyer, por seu turno, afirma que é possível descrever o perigo abstrato como um estado tal que não pode ser deixado à competência de avaliação do agente em virtude dos riscos ligados ao modo de comportamento levado a cabo por aquele. Assim, segundo este autor, caracteriza-se o estado ou situação de perigo abstrato meramente pelo fato de que a ausência de uma lesão depende tão-só de circunstâncias que não guardam relação com o tipo, as quais, conforme a visão do legislador, é melhor que não venham a ocorrer ${ }^{6}$.

Segundo Martin não apenas é possível se falar em um perigo abstrato, como este consiste em um risco de lesão para o bem jurídico juridicamente desaprovado sob uma perspectiva $e$ ante $^{7}$. Este autor sustenta que, assim como na caracterização do perigo concreto concorre uma avaliação normativa como resultado, esta avaliação também pode se estender aos crimes de perigo abstrato. A idoneidade ex ante da ação para que se crie um risco proibido é, portanto, uma condição necessária para este tipo de delito.

A importância da contribuição deste autor repousa, também, no fato de ela não se alicerçar na clássica definição de resultado, segundo a qual resultado é só a lesão ou a produção de um perigo concreto. Para Martin, o conceito de resultado permite uma extensão maior. Assim, afetação do objeto de ação é o resultado dos crimes de lesão; a probabilidade da superveniência da lesão avaliada ex post factum é o resultado dos crimes de perigo concreto e, por fim, o risco juridicamente desaprovado criado sob uma perspectiva ex ante é o resultado dos crimes de perigo abstrato ${ }^{8}$.

As distintas concepções de resultado, em verdade, resultam de uma falsa equiparação entre o que se entende por crime de lesão e crime de resultado. Assim, acentua Amelung que

O resultado típico é fundamentalmente separado do resultado de lesão ao bem jurídico. Ambos são apenas idênticos lá onde o resultado de lesão ao bem

Strafrecht. Duncker \& Humboldt: Berlin, 1991, p.23; JESCHECK, Hans-Heinrich/ WEIGEND, T. Lehrbuch des Strafrecht, Allgemeiner Teil, 5.ed, Duncker \& Humboldt, 1996, § 26, II 2, p. 264.

${ }^{5}$ WOHLERS, Wolfgang. Deliktstypen des Präventionsstrafrechts - zur Dogmatik ,,moderner”

Gefährdungsdelikte. Berlin: Dunckler und Humblot, 2000, p. 282.

${ }^{6}$ HOYER, Andreas. Zum Begriff der ,abstrakten Gefahr”. In: Juristische Arbeitsblätter, 1990, pp. 183, 188, passim..

${ }^{7}$ MARTIN, Jörg. Strafbarkeit grenzüberschreitender Umweltbeeinträchtigungen: zugleich ein Beitrag zur Gefährdungsdogmatik und zum Umlweltvöllkerrecht. Freiburg I. Br.: Max-Planck-Institut für Ausländisches und Internationales Strafrecht, 1989, p. 83.

${ }^{8}$ MARTIN. Umweltbeeinträchtigungen, pp. 33, 34. 
jurídico pertence à consumação do tipo. Dentro do resultado típico pode-se, ainda hoje, defender concepções com dois conceitos. O conceito restrito de resultado engloba apenas o resultado, que se desenvolve na sequência da execução da ação. $O$ conceito amplo de resultado inclui a ação como tal, na qual o tipo não requer outros efeitos, isto é, como no caso dos crimes de mera conduta 9 .

Assim, enquanto a classificação entre crimes de resultado faz referência à relação que se dá entre a conduta e o objeto de ação, conforme o conhecido critério (naturalístico) do lapso espácio-temporal entre este e aquela, a classificação entre crimes de lesão e perigo diz respeito à relação entre conduta e bem jurídico ou objeto jurídico de proteção.

2.2 O que se entende por crime de perigo abstrato: seu conceito e legitimidade.

O que se entende por delito de perigo abstrato é, ainda, um ponto controverso, como se depreenderá das distintas formulações oferecidas pela doutrina e, a seguir, expostas em suas linhas gerais. Antes de aduzir tais posições, contudo, é possível estabelecer algumas características (não unânimes) que parecem se repetir entre aquelas: a) a punição independente de uma lesão ou produção de um estado de perigo concreto ao bem jurídico; b) o fundamento básico da incriminação ligado a um motivo ou razão político-criminal do legislador; c) as características da atividade como aspecto crucial para a determinação do crime e a presunção legislativa de que tais atos, se praticados, de acordo com regras da experiência, podem gerar situações perigosas e d) a vinculação de tais delitos a uma noção de segurança para o livre desenvolvimento de direitos e bens individuais.

aa) $O$ crime de perigo abstrato como conceito negativo: a desnecessidade do perigo concreto e o apelo às razões do legislador.

Os delitos de perigo abstrato (abstrakte Gefährdungsdelikte) são, muitas vezes, definidos de maneira negativa pela doutrina. Para Kindhäuser, por exemplo, são denominados

\footnotetext{
${ }^{9}$ AMELUNG, Knut. Rechtsgüterschutz und Schutz der Gesellschaft. Untersuchungen zum Inhalt und zum Anwendungsbereich eines Strafrechtsprinzip auf dogmengeschichtlicher Grundlage. Zugleich ein Beitrag zur Lehre von der „Sozialschädlichkeit” des Verbrechens.Frankfurt/M: Anthenäum Verlag, 1972., p. 211. Trecho original: Der tatbestandsmäßige Erfolg ist vom Rechtsgutsverletzungserfolg grundsätzlich zu trennen. Beide sind nur dort identisch, wo die Rechtsgutsverletzung zur Vollendung des Tatbestandes gehört. Innerhalb der tatbestandsmäßigen Erfolge kann man MIT einer heute noch immer vertretenen Aufassung zwei Begriffe unterscheiden. Der engere Erfolgsbegriff umfaßt nur das Ereignis, das sich im Anschluß na den Vollzug der Handlung entwickelt. Der weitere Erfolgsbegriff schließt die Handlung MIT ein und ist dort, wo ein Tatbestand keine weiteren Wirkungen verlangt, d.h. bei den schlichten Tätigkeitsdelikten, mit der Handlung identisch.
} 
delitos de perigo abstrato aqueles cujas normas de conduta não proíbem nem uma colocação concreta em perigo, nem tampouco a lesão a um bem jurídico ${ }^{10}$.

De acordo com Wessels/Beulke

os delitos de perigo abstrato baseiam-se, ao contrário, na presunção legal de que determinado tipos de conduta, em geral, são perigosos para o objeto de proteção [...]. A perigosidade da ação não é aqui um elemento do tipo, mas apenas a razão para existência da proibição, de modo que o julgador, normalmente, não tem de provar se uma colocação em perigo ocorreu ou não no caso concreto ${ }^{11}$.

Harro Otto assevera que os delitos de perigo abstrato consistem em um comportamento tipicamente perigoso que é proibido independentemente de no caso concreto ocorrer ou não um perigo. O legislador quer, assim, através da punição desse tipo de comportamento prevenir casualidades perigosas, por um lado, e por outro assegurar a proteção de instituições e regulações que permitem o desenvolvimento pessoal ${ }^{12}$.

Para Maurach, nos delitos de perigo abstrato, a conduta normalmente perigosa fica sob ameaça de pena sem que precise de um resultado de perigo no caso concreto. A prevenção de perigos concretos e lesões é, portanto, apenas um motivo do legislador, sem que sua existência seja pressuposta tipicamente ${ }^{13}$.

\section{bb) A concepção de Binding}

É impossível entender a opinião de Binding acerca dos crimes de perigo e, sobretudo, ao que atualmente se chama de delito de perigo abstrato, sem alguma alusão á sua teoria das normas. As normas para Binding servem à proteção de bens jurídicos e, portanto, não são um fim em si mesmas. Pois "todas as proibições têm um fim: elas desejam impedir que as ações humanas deem causa a certas modificações no mundo jurídico" ${ }^{14}$. Enquanto o meio consiste na criação de normas, o fim é a proteção de bens jurídicos ${ }^{15}$. Deste modo, a proteção de bens jurídicos aparece como razão para criar normas.

\footnotetext{
10 KINDHÄUSER, Urs. Gefährdung als Straftat: rechtstheoretische Untersuchungen zur Dogmatik der abstrakten und konkreten Gefährdungsdelikte. Klostermann: Frankfurt am Main, 1985, p.225.

${ }^{11}$ WESSELS, Johannes; BEULKE, Werner. Strafrecht Allgemeiner Teil. Die Straftat und ihr Aufbau. 32.ed. CF Müller verlag: Heidelberg, 2009, $\S 1^{\circ}$, Rn 29, p. 8 .

12 OTTO, Harro. Grundkurs Strafrecht. Allgemeine Strafrechtslehre. 7.Auflage. Berlin: Walter de Gruyter, 2004, § 4 ${ }^{\circ}, \mathrm{Rn} 14$.

${ }^{13}$ MAURACH, Reinhart; ZIPF, Heinz. Strafrecht Allgemeiner Teil. 8.Auflage. München: Beck, 1992, § 20 III, Rn 31.

${ }^{14}$ BINDING, Karl. Die Normen und ihre Übertretung. Eine Untersuchung über die rechtmäßige Handlung und ihren Arten des Delikts. 4.Auflage. Leipzig: Weidmann, 1922, p. 325.

${ }^{15}$ Ibidem., p. 365.
} 
Importante é notar que, para Binding, todos os delitos contêm uma desobediência ${ }^{16}$, de modo que "o momento da desobediência está presente em toda contrariedade à norma"17. Isto quer dizer que a desobediência é um elemento comum a todos os crimes, mas a partir disto não se deduz que o delito nela se esgota, pois tal conceito corresponde, senão, a uma ponderação corrente em direito penal: grosso modo, a de que só se pode proibir ações, mas não modificações no mundo jurídico (em outras palavras, não se proíbe o resultado).

O delito corresponde, portanto, a dois objetos de agressão, a saber: à lesão a direitos subjetivos de obediência e à lesão de bens jurídicos ${ }^{18}$. Para Binding, os delitos se dividiam, portanto, em dois grupos, a saber: os delitos de lesão e os delitos de perigo. No caso dos delitos de lesão, ao lado da agressão ao direito subjetivo de obediência ao estado, existe uma lesão a bens jurídicos. Destarte, um delito de lesão é realizado quando o autor viola a proibição de causar um dano e, por isso, produz o resultado ${ }^{19}$.

Releva notar que o momento da desobediência retrocede a um ponto anterior à lesão do bem jurídico, de modo que a obediência à norma é só um meio para se alcançar a proteção de bens jurídicos ${ }^{20}$. O ponto de gravidade repousa, assim, na lesão ao bem jurídico, pois o direito é atingido por meio de ações em suas aspirações mais preciosas. O fim de preservação do direito é frustrado através da destruição, de modo que "seria preferível o autor desobedecer a norma dez vezes a conseguir seu intento uma única vez"21.

Por seu turno, tanto os delitos de perigo como os de lesão pertencem a uma mesma categoria denominada delitos de agressão (Angriffsdelikte), pois há uma igualdade essencial do momento do delito entre ambas as espécies e uma diferença entre os delitos de perigo e as meras proibições (schlechtin Verbote) ou a simples desobediência (einfache Umgehorsam). A igualdade essencial entre as normas que proíbem lesões e as que proíbem o perigo repousa no fato de que através da criação de uma proibição de perigo, também a afetação do bem jurídico será proibida, não através da lesão ou destruição em si, mas mediante a colocação deste bem em perigo ${ }^{22}$.

Assim, Binding entende a colocação em perigo como o abalo da existência de segurança do bem jurídico ${ }^{23}$, sendo certo que, aqui, já há um resultado, um dano material

\footnotetext{
${ }^{16}$ Este seria o único sentido em que é correto falar em lesão a direitos subjetivos segundo Binding, isto é, a lesão de direitos subjetivos de obediência. Cf. Ibidem., p. 98.

${ }^{17}$ Ibidem., p. 186, 326.

${ }^{18}$ Ibidem., p. 327.

${ }^{19}$ Ibidem., p. 364.

${ }^{20}$ Ibidem., p. 365.

${ }^{21}$ Ibidem., p. 366.

${ }^{22}$ Ibidem., p. 374.

${ }^{23}$ Ibidem., p. 372-373.
} 
como núcleo. Pois, "assim como no caso da violação da proibição de uma lesão, a desobediência contém uma destruição ou lesão, no caso dos delitos de perigo a desobediência revela igualmente um dano material como núcleo: uma afetação dos bens jurídicos postos em perigo em sua existência imperturbada" 24 .

Portanto, a distinção entre delitos de perigo e a simples desobediência repousa na circunstância de que na simples desobediência a colocação em perigo do bem jurídico é meramente o motivo do legislador para criar um comando proibitivo, enquanto no caso dos delitos de perigo, a produção deste aparece como elemento do conceito da ação proibida ${ }^{25}$.

Por conseguinte, sustenta Binding que, no caso de este perigo não existir ou de ser neutralizado, a proibição deste perde o seu sentido. A norma proibitiva da colocação em perigo de um bem seria, assim, uma proibição sob a condição tácita de que, quando da ação, não ocorra um perigo ${ }^{26}$.

cc) Hirsch e a perigosidade concreta e abstrata.

Hans Joachim Hirsch ${ }^{27}$, por sua vez, propõe que a costumeira dicotomia "delitos de perigo concreto e abstrato" seja substituída por uma outra classificação, igualmente dicotômica, mas com conteúdo distinto. Destarte, defende o autor a existência de um primeiro grupo de delitos com resultado de perigo concreto (konkrete Gefahrerfolgsdelikte) e, por outro lado, os delitos de perigosidade (Gefährlichkeitsdelikte) ou de risco (Risikodelikte), que poderiam apresentar uma natureza concreta ou abstrata. O perigo (Gefahr) é objeto dos delitos de perigo concreto, que para o direito são classificados como delitos de resultado, pois o perigo representa um estado de coisas objetivo. Já os delitos de perigosidade não são estados, mas relacionam-se a uma atividade.

Conforme mencionado, dentro do grupo dos delitos de perigosidade ou de risco Hirsch distingue os delitos de perigosidade concreta e abstrata. A existência de um ou de outro depende da ocorrência de uma verdadeira perigosidade concreta ou de uma perigosidade geral. Para esta segunda hipótese, a terminologia "delito de perigo abstrato" é, segundo Hirsch, inexata, pois não se trata da generalização da superveniência de um perigo como resultado, mas sim de determinadas características ou elementos que possui a ação ou

\footnotetext{
${ }^{24}$ Ibidem., p. 374.

${ }^{25}$ Ibidem., pp. 123, 373-374

${ }^{26}$ Ibidem., p. 386.

${ }^{27}$ Cf. HIRSCH, Hans-Joachim. Gefahr und Gefährlichkeit, in: Strafgerechtigkeit. Festschrift fürArthur Kaufmann, 1993, pp. 545, 548 e 557.
} 
atividade. Grosso modo, os delitos com resultado de perigo concreto são, pois, delitos de resultado. Os delitos de perigosidade são meros delitos de atividade.

Junto ao perigo, enquanto característica dos delitos de perigo concreto, está também a chamada prognose póstuma objetiva como critério delimitador. Ou seja, um julgador experto, inteligente e imaginário que se põe, em uma relação espácio-temporal, diante das circunstâncias objetivas disponíveis acerca da situação do bem jurídico. Em termos claros, a prognose póstuma objetiva se dá sob a perspectiva do bem ameaçado, e não do ponto de vista do autor da conduta.

Ao contrário, nos delitos de perigosidade concreta, a altura do risco é determinada sob a perspectiva da situação do agente que pratica a conduta. Segundo Hirsch, como visto, a perigosidade pode ser concreta ou abstrata. Se a avaliação parte da perspectiva da situação do autor, a possibilidade real de uma lesão surge da ação praticada. Esta possibilidade deverá ser analisada em cada caso. Se ex ante, do ponto de vista do autor, existia um risco concreto, então se trata de um delito de perigosidade concreta, dotado de uma antijuridicidade material que representa real possibilidade de lesão a um bem jurídico. Caso contrário, há somente um "risco abstrato", que configura mera desobediência formal à norma.

dd) Kindhäuser: a possibilidade de uma disposição segura sobre os bens jurídicos à luz da norma de conduta.

Para Urs Kindhäuser, a legitimação da proibição dos chamados delitos de perigo abstrato deve repousar no plano das normas de conduta sobre a ideia de disposição tranquila ou segura de bens jurídicos.

Isto significa, essencialmente, uma mudança de perspectiva: não mais a agressão ao bem jurídico, por parte do autor, é tomada como ponto de partida, mas sim a análise da segura disponibilidade de bens jurídicos desde a perspectiva da vítima ${ }^{28}$.

De acordo com este autor, o fim da norma está limitado ao âmbito de sua validade. As normas têm como objeto modos de comportamento que não são definidos mediante uma consequência específica da conduta. Assim, nem os delitos de perigo abstrato e nem os de perigo concreto são vistos como consequências de um comportamento com características

\footnotetext{
${ }^{28}$ KINDHÄUSER, Urs. Op. Cit., pp. 163, 337. Tal mudança de perspectiva integra o que o autor chama do paradigma da agressão que, habitualmente, incorpora um critério espácio-temporal, típico dos crimes de lesão ou resultado. Segundo Kindhäuser, tal paradigma deve ser mudado para uma perspectiva que, no campo do perigo, parta da premissa da esfera segura de disposição ou disponibilidade de bens jurídicos (que constituem meios para o livre desenvolvimento pessoal).
} 
lesivas específicas. A evitação de lesões a bens jurídicos é o fim de todas as normas, e não só apenas o fim das proibições de lesão ${ }^{29}$.

O fim do direito está, portanto, na possibilitação do livre desenvolvimento do cidadão através de uma segura coordenação de sua esfera de liberdade. Os meios para o livre desenvolvimento do cidadão são os bens (Güter), que o direito penal protege através de duas considerações distintas. Na primeira, há um interesse na integridade substancial dos bens, enquanto, em uma segunda consideração, o interesse vincula-se à livre ou tranquila disposição (gefahrelosen Verfügung über Güter) sobre bens objetos da garantia normativa. A proteção neste último sentido refere-se diretamente aos delitos de perigo abstrato e concreto; enquanto a proteção no primeiro sentido dirige-se aos delitos de lesão ${ }^{30}$.

O fim da proibição de perigos abstratos deve, pois, evitar a lesão ou colocação em perigo dos bens jurídicos. Isto não significa que o fim da proibição do delito de perigo abstrato deva ser totalmente independente dos fins das normas de outros tipos de delitos. Isto quer dizer apenas que os fins não devem ser idênticos. Trata-se, pois, de um fim intermediário, cuja falha em sua realização (relativa à lesão ou colocação em perigo) comprova um conteúdo desvalorado independente e autônomo que se liga à proteção de bens jurídicos ${ }^{31}$.

O autor prossegue, afirmando que os esforços do discurso jurídico e da literatura especializada em compatibilizar as normas dos delitos de perigo abstrato com o postulado de proteção de bens jurídicos estão, por enquanto, de um modo estranho preocupados com a opinião de que o fim da proibição de uma conduta abstratamente perigosa deva ser a de evitar lesões a bens jurídicos. No entanto, é preciso ou determinar a referência ao bem jurídico, por exceção, independentemente de uma violação deste, ou explicitar um alargamento do tipo para incluir uma concreta violação na subsunção típica ${ }^{32}$.

Para Kindhäuser, o ponto de referência da pena criminal é a perda de validade que a norma sofre quando de sua violação. A compensação quer significar o contrabalanço simbólico do déficit na motivação da confiança no direito ${ }^{33}$. Assim, somente se não é possível mais garantir a segurança de modo suficiente através do desencorajamento inerente à proibição, a pena é tomada em consideração ao invés da opção de multa. Para Kindhäuser, a supressão ou recusa de todos os delitos de perigo abstrato no direito penal conduz a uma

\footnotetext{
${ }^{29}$ Ibidem, p. 14.

${ }^{30}$ Ibidem, p.26.

${ }^{31}$ Ibidem, p. 227.

32 Ibidem, p. 227.

${ }^{33}$ Ibidem, p.343.
} 
desvalorização das normas, que são as condições elementares de proteção de uma coexistência livre ${ }^{34}$.

À guisa de conclusão, pode-se dizer que Kindhäuser pretende justificar a razão de ser dos delitos de perigo abstrato ao enxergar o aspecto decisivo no fato de que estes delitos significam uma afetação normativa da segurança garantida. Pois quando se fala em garantia da segurança, deve-se evitar tampouco demonstrar os efeitos lesivos de um comportamento ${ }^{35}$.

Destarte, a segurança da possibilidade de se dispor dos bens é parte legítima do princípio de proteção aos bens jurídicos, pois estes são definidos como meios que servem ao livre desenvolvimento pessoal ${ }^{36}$. O efeito da ação perigosa consiste em uma - ainda que de baixa duração - afetação da disposição sobre um bem. Haveria, pois, uma lesão sui generis ${ }^{37}$. Por exemplo, a ultrapassagem proibida realizada por um motorista em uma curva com baixa visibilidade, mesmo que nenhum automóvel venha na direção contrária, é uma lesão da segurança da via, pois outros motoristas devem poder confiar que ninguém realizará uma ultrapassagem proibida ${ }^{38}$.

\section{ee) Os delitos de perigo abstrato como espécie de negligência}

Alguns autores defendem a concepção de que os delitos de perigo abstrato são delitos de negligência. Seu conteúdo coincide, portanto, com o elemento objetivo da inobservância do cuidado devido ${ }^{39}$.

Os delitos de perigo abstrato são, pois, "delitos culposos específica e expressamente modalizados" ${ }^{\Perp 0}$. O tipo penal do delito de perigo abstrato caracteriza-se, destarte, por descrever ações "que são negligentes no que diz respeito à superveniência da lesão de um determinado bem jurídico, mas são puníveis independentemente de a lesão ao bem jurídico realizar-se ou não de fato" ${ }^{41}$. Esta inobservância objetiva de um cuidado devido deve se referir, contudo, ao bem jurídico para que o autor seja punido por um delito de perigo abstrato.

Brehm também se utiliza da figura da negligência sem consequências para definir o

\footnotetext{
${ }^{34}$ Ibidem, p. 345.

${ }^{35}$ Ibidem, p. 290.

${ }^{36}$ Ibidem, p. 283.

${ }^{37}$ Ibidem, p. 211.

${ }^{38}$ Ibidem, p. 292.

${ }^{39}$ Assim HORN. Eckhard. Konkrete Gefährdungsdelikte. Köln: Schmidt, 1973; BREHM, Wolfgang. Zur

Dogmatik des abstrakten Gefährdungsdelikts. Dissertation Tübingen, 1973.

${ }^{40}$ HORN, Eckhard. Op.cit., p. 23

${ }^{41}$ Idem., p. 28.
} 
conteúdo dos crimes de perigo abstrato ${ }^{42}$. A punibilidade do crime de perigo abstrato, contudo, está vinculada à violação de um dever de cuidado que não é meramente formal. Assim, segundo Brehm, para que haja de fato punição a título de delito de perigo abstrato é preciso avaliar se a ação era idônea à produção de um resultado típico desde uma perspectiva ex ante. A afirmação dessa idoneidade é, justamente, o que dá ao dever um conteúdo material $^{43}$.

\section{ff) A concepção da superveniência do risco.}

Para Volz o ponto curial da proibição inerente aos delitos de perigo abstrato está não apenas no fato de certas ações com certa freqüência levarem a resultados indesejáveis, mas, sobretudo, em razão de o autor não ativar ou tentar aplicar cuidados para, na prática, arrostar o perigo criado. Há, portanto, a lesão de um dever, a qual representa a superveniência do risco em face do bem jurídico sem levar em conta uma prognose sobre as consequências da conduta $^{44}$.

Se o critério determinante reside, pois, na realização de uma prognose quanto às consequências da ação e da aplicação de fatores que possam arrostar o perigo, então, o tipo penal estará excluído quando, apesar de o comportamento formalmente lograr subsunção, o agente houver arrostado o perigo e, assim, livrado, de acordo com sua avaliação, qualquer perigo para o bem jurídico tutelado ${ }^{45}$.

\section{gg) A probabilidade de perigo concreto.}

Peter Cramer, por seu turno, compreende o perigo abstrato como a probabilidade de um perigo concreto ${ }^{46}$. Este autor parte da premissa de que todo comportamento punível deve comprovar sua relação com o bem jurídico. Esta relação, segundo Cramer, nos delitos de perigo abstrato se expressa da seguinte maneira:

No caso dos delitos de perigo essa relação vem expressa diretamente na intensidade delituosa da ação. Dada a menor ou maior probabilidade da superveniência de um dano, deve se descrever a perigosidade abstrata como uma etapa precursora do perigo concreto; o desvalor da relação entre ambos os tipos de

\footnotetext{
${ }^{42}$ BREHM, Wolfgang. Op.cit., p . 127.

${ }^{43}$ Idem., pp. 93, 126, 131.

${ }^{44}$ VOLZ, Manfred. Unrecht und Schuld abstrakter Gefährdungsdelikte. Dissertation Göttingen, 1968, pp. 29, 143, 147.

${ }^{45}$ Idem., p. 167.

${ }^{46}$ CRAMER, Peter.Vollrauschtatbestand als abstraktes Gefährdungsdelikt. Tübingen : J.C.B. Mohr (Paul Siebeck), 1962, p.68 et seq.
} 
colocação em perigo corresponde, com isto, à relação entre os diferentes níveis de realização do delito, donde aqui se caracteriza a perigosidade do comportamento e não apenas do autor. Da possibilidade de se incluir os delitos de perigo abstrato numa relação de desvalor resulta conclusivamente a consequiência de que este tipo de delito aparece como desvalorado e com isto punível ${ }^{47}$.

Essa concepção é, contudo, criticável, pois, em verdade, importa em definir o perigo abstrato como uma probabilidade da probabilidade de um perigo concreto.

hh) A exigência da refutabilidade da presunção do perigo.

Esta compreensão é defendida, sobretudo, por Schröder, para quem a presunção do risco ou do perigo para o bem jurídico deve ser passível de contraprova (Gegenbeweis). Esta necessidade da contraprova só seria exigível, contudo, em um primeiro grupo de delitos de perigo abstrato, os quais guardam conexão com objetos concretos e passíveis de refutação empírica. Deste modo, nesses casos, o autor não será punível quando a conduta por ele praticada não puder conduzir a qualquer perigo imaginável para a convivência humana. Já quando não for possível identificar um objeto suscetível de contraprova, a manutenção da proibição se justifica através da presunção porque, em primeiro lugar, a possibilidade de contraprova seria enormemente dificultada e, em segundo lugar, a viabilidade do ordenamento seria posta em xeque, como, por exemplo, no crime de porte de armas (Waffenbesitz) e no de tráfico de drogas (Rauschgifthandel) ${ }^{48}$.

\section{ii) Outras concepções}

Entre os muitos autores que dispensaram alguma atenção ao problema de legitimação dos crimes de perigo abstrato, pode-se citar mais alguns que lograram algum relevo na doutrina.

Bernd Schünemann divide os delitos de perigo abstrato em três grupos, a saber: a) o que se refere a lesão de bens jurídicos espiritualizados e intermediários (vergeistigte

\footnotetext{
${ }^{47}$ Idem., p. 65. Trecho original: "Bei den Gefährdungsdelikten kommt diese Beziehung in der verbrecherischen Intensit6at der Handlung unmittelbar zum Ausdruck. In Anbetracht der geringeren oder größeren Wahrscheinlichkeit für den Eintritt eines Schadens wird man die abstrakte Gefährlichkeit als Vorstufe der konkreten Gefahr bezeichnen müssen; das Unwertverhältnis zwischen diesen beiden Gefährdungstypen entspricht damit der Beziehung zwischen den verschiedenen Verwirklichungstufen des verbrechens, wobei e shier die Gefährlichkeit des Verhaltens und nicht nur die Gefährlichkeit des Verbrechers kennzeichnet. Aus der Möglichkeit, die abstrakten Gefährdungsdelikte in ein Unwertverhältnis einzubeziehe, ergibt sich schließlich die Konsequenz, daß diese Deliktsart wertwidrig und damit strafwürdig erscheint".

${ }^{48}$ SCHRÖDER, Horst. Die Gefährdungsdelikte im Strafrecht. In: Zeitschrift für die gesamte

Strafrechtswissenschaft, 81 (1969), p. 16 et seq.
} 
Zwischenrechtsgüter) como na hipótese dos crimes de corrupção; b) os chamados delitos ou comportamentos em massa (Massenhandlungen), justificáveis por razões pedagógicas, como, por exemplo, alguns delitos de trânsito e c) um terceiro grupo que poderíamos chamar de delitos de perigo abstrato em sentido estrito.

Ao contrário de Brehm e Horn, Schünemann condiciona a punibilidade à inobservância das precauções devidas desde a perspectiva subjetiva do autor. Assim, a conduta do agente já será punível caso ele apenas deixe de tomar as precauções devidas de acordo com a sua visão ou perspectiva. Por meio desta concepção é defensável o princípio do consenso mínimo, da base mínima de concordância entre os cidadãos, de modo que a punição de tais comportamentos aparece como legítima e adequado ao princípio da culpabilidade ${ }^{49}$.

Jürgen Wolter, por outro lado, enxerga o crime de perigo abstrato dentro de sua própria concepção de imputação objetiva e individual em um sistema eminentemente funcionalista, baseado no direito penal do risco. Os delitos de perigo abstrato encerram, assim, uma espécie de injusto primário do resultado (primäres Erfolgsunrecht). Conforme sustenta este autor, o protótipo do injusto deve ser a criação de um risco objetivamente real juridicamente desaprovado. Neste sentido, o autor desde já recusa o injusto da tentativa inidônea, uma vez que ela não cria um risco real para bens jurídicos. $\quad$ Em síntese, o injusto da conduta há de ser associado ao injusto do risco ou da perigosidade (Gefährlichkeitsunrecht). É, portanto, da relação de perigo entre a conduta e o resultado que surge a pretensão de tutela ao bem jurídico ${ }^{50}$

Wolter divide os delitos de perigo abstrato em delitos próprios e impróprios. O primeiro grupo se justifica não só por razões pedagógicas ou pelas dificuldades de prova, mas também pelo fato de exercerem tais delitos um importante papel de controle e vigilância ${ }^{51}$. $\mathrm{O}$ grupo dos delitos de perigo abstrato impróprios caracteriza-se pela criação culposa ou dolosa de um risco adequado à lesão do bem jurídico, caso contrário violar-se-ia o princípios do injusto penal e o da culpabilidade ${ }^{52}$.

Abandonando a argumentação baseada exclusivamente no risco, Berz sustenta que a legitimidade dos delitos de perigo abstrato se explicam com base na lesão da confiança dos

\footnotetext{
${ }^{49}$ SCHÜNEMANN, Bernd. Moderner Tendenzen in der Dogmatik der Fahrlässigkeits- und Gefährdungsdelikte. In: Juristische Arbeitsblätter, 1975, p. 798 et seq.

${ }^{50}$ WOLTER, Jürgen. Objektive und personale Zurechnung von Verhalten. Gefahr und Verletzung in einem funktionalen Straftatsystem. Berlin, 1981, p. 356. Também em: WOLTER, Jürgen. Imputación objetiva y personal a titulo de injusto. A la vez, una contribución al estúdio de la aberratio ictus. In: (Hrsg.) SCHÜNEMANN, Bernd. El sistema moderno del Derecho penal: cuestiones fundamentals. Madrid: tecnos, 1991, p. 108 et seq.

${ }^{51}$ WOLTER, Jürgen. Objektive und personale Zurechnung...p. 277.

${ }^{52}$ Idem., p. 278.
} 
demais amigos do direito ${ }^{53}$. Apenas quando toda a perigosidade da ação possa ser negada é que estará excluído o injusto, bem como restará inexistente a quebra da confiança ${ }^{54}$.

3. Os diferentes tipos de perigo abstrato

Dentre os autores que defendem a existência e legitimidade dos delitos de perigo abstrato, algumas subcategorias tornaram-se mais aceitas e difundidas. Conforme acentua com razão Wohlers, o conjunto de condutas sob a égide da nomenclatura "delitos de perigo abstrato" não constituem um tipo de delito uniforme, mas trata de um complexo de tipos penais heterogêneos com potenciais de risco e particularidades bastante distintas entre $\mathrm{si}^{55}$. Este tópico apresentará, sem a pretensão de ser exaustivo, os principais tipos.

\subsection{Delitos de idoneidade ou aptidão (Eignungsdelikte).}

Delitos de idoneidade ou aptidão são aqueles nos quais uma ação é proibida desde que ela seja adequada a lesionar um determinado bem jurídico, como expressão idônea a produzir perigo. A efetiva lesão do bem jurídico, contudo, não é parte da estrutura do delito de aptidão $^{56}$. A aptidão não resulta de uma análise ex ante do perigo, mas de qualidades objetivas específicas da atividade ou conduta desenvolvida ${ }^{57}$. Conforme sublinha Schröder, a aptidão, aqui, é uma ação ou conduta que pode conduzir a um determinado resultado, o qual pode ser um perigo concreto ou uma lesão ${ }^{58}$.

\subsection{Delitos preparatórios (Vorbereitungsdelikte)}

Segundo Wohlers, os delitos preparatórios consistem em condutas cujo potencial de risco consiste no fato de a própria pessoa que atua, ou uma outra, poder apoiar-se no resultado da conduta prévia em questão. Tais delitos podem se referir tanto a bens individuais como a

\footnotetext{
${ }^{53}$ BERZ, Ulrich. Formelle Tatbestandsverwirklichung und materialer Rechtsgüterschutz. Eine Untersuchung zu den Gefährdungs- und Unternehmensdelikten. München, 1986, p. 114.

${ }^{54}$ Ibidem.

${ }^{55}$ WOHLERS, Wolfgang. Deliktstypen... p. 25.

${ }^{56}$ HOYER, Andreas. Die Eignungsdelikte. Duncker \& Humboldt: Berlin, 1987, p.198.

${ }^{57}$ Idem, p. 107.

${ }^{58}$ SCHRÖDER, Horst. Op.cit, pp.7, 22
} 
$\operatorname{coletivos}^{59}$. Assinala o autor que, não raro, concorre uma combinação entre delitos preparatórios e cumulativos ${ }^{60}$.

Entre as objeções a esta classificação estão os argumentos de que não se pode imputar a responsabilidade de desdobramentos posteriores levados a cabo por terceiros à conduta de quem atuou em primeiro lugar, bem como o fato de a figura dos delitos de preparação não considerarem a previsibilidade ou imprevisibilidade da conduta posterior ${ }^{61}$. Wohlers procura responder tais objeções valendo-se do princípio da adequação social da conduta e da confiança $^{62}$.

\subsection{Delitos cumulativos (Kumulationsdelikte)}

Tais delitos consistem nas condutas que por si só não podem lesionar ou lesionam em medida irrisória um determinado bem jurídico protegido. Todavia, quando unidas a outras condutas realizadas na mesma direção podem gerar um dano significativo. A principal aplicação destes delitos ocorre no âmbito dos bens jurídicos supraindividuais, difusos ou coletivos, como, por exemplo, nos crimes contra o meio ambiente ${ }^{63}$.

Tal figura recebeu muitas críticas. Além do risco da criminalização de bagatelas, como se depreende do parágrafo anterior, há também a acusação de que os delitos de cumulação fazem do injusto individual um injusto coletivo, já que pressupõem a responsabilidade de terceiros. É um instituto que conta demasiadamente com êxito do chamado risco de imitação da conduta, que deve ser verossímil ou provável para que se possa falar em cumulação.

Os delitos de cumulação ${ }^{64}$ nascem, tal qual a ideia dos crimes de perigo abstrato, em grande medida, da sociedade de risco. A crescente complexidade dos processos técnicos, a respeito dos quais, não raro, ignora-se possíveis efeitos ou transtornos, exige uma constante precaução em termos de segurança. De fato, o progresso tecnológico e todas as suas

\footnotetext{
${ }^{59}$ WOHLERS, Wolfgang. Deliktstypen... p. 310; WOHLERS, Wolfgang. Teoria del bien jurídico y estructura del delito. Sobre los criterios de una imputación justa. Traduzido do original: Rechtsgutstheorie und Deliktsstruktur - zu den Kriterien fairer Zurechnung. In: HEFENDEHL, Roland (ed). La teoria del bien juridico. Fundamento de legitimación del derecho penal o juego de abalorios dogmático? Marcial Pons: Madrid, 2006, p. 288 et seq. Como exemplos de delitos de preparação: a posse de armas ou de substâncias nocivas que são condutas, em si, não perigosas, mas que podem gerar lesões posteriores.

${ }^{60}$ WOHLERS, Wolfgang. Teoria del bien jurídico...p. 288 et seq.

${ }^{61}$ Idem., pp. 291-292

${ }^{62}$ Idem., p. 293 et seq.

${ }^{63}$ Ibidem, p.229 et seq.

${ }^{64}$ Os delitos de cumulação nasceram com Kuhlen em 1986: Cf. KUHLEN, Lothar. Der Handlungserfolg der strafbaren Gewässerverunreinigung (\$ 324StGB), GA, 1986, p.389 et seq. Mais recentemente em: KUHLEN, Lothar. Umweltstrafrecht - auf der Suche nach einer neuen Dogmatik. In: Zeitschrift für die gesamte Strafrechtswissenschaft, 105, 1993, p. 697.
} 
idiossincrasias, para bem ou para mal, são um fato. A revolução tecnológica em si, porém, não dará a resposta para estas indagações, mas tão-só a formulação de novas bases de comportamento ético individual-coletivo. Há, contudo, quem entenda que o direito penal não é o instrumento adequado (em virtude da gravidade de sua intervenção na vida dos

particulares) para promover este processo coletivo de reeducação e conscientização ${ }^{65}$.

Conforme argumenta Wohlers, os delitos de acumulação fundam-se em um dever de cooperação social, segundo o qual para os membros de uma sociedade organizada politicamente, os deveres jurídicos individuais não se limitam ao mero respeito do não lesionar o direito alheio, mas incluem a obrigação de colaborar para garantir o fato de que cada um possa receber o que lhe é de direito ${ }^{66}$.

\subsection{Delitos de perigosidade concreta (konkrete Gefährlichkeitsdelikte)}

Como explica Wohlers, tal espécie trata de condutas cuja perigosidade reside no fato de que elas conduzem a situações que já não são passíveis de domínio ou controle pelo autor. Quando o objeto de proteção correspondente adentra o âmbito de atuação do agente, pode haver um resultado de perigo relevante para o bem jurídico, ou mesmo uma lesão ${ }^{67}$. Exemplo costumeiro é o do agente que dirige embriagado.

\subsection{Delitos de massa (Massenhandlungen)}

São considerados um tipo de perigo abstrato justificado por razões de prevenção geral e, também, pedagógicas (lerntheoretischen), muito comuns no direito penal de trânsito. A punibilidade aqui é afirmada ainda que no caso concreto não haja um perigo real ${ }^{68}$.

3.6 Delitos de potencial lesivo

\footnotetext{
${ }^{65}$ SILVA DIAS, Augusto. "What if everybody did it?": sobre a (in)capacidade de ressonância do Direito Penal à figura da acumulação. In: RPCC, ano 13, 2003. p. 314.

${ }^{66}$ WOHLERS, Wolfgang. Teoria del bien jurídico...p. 300.

${ }^{67}$ Ibidem, p.290.

${ }^{68}$ ROXIN, Claus. Strafrecht. Allgemeiner Teil. 4.Auflage. München: C.H. Beck, 2006, p. 430.
} 
Trata-se de uma concepção similar àquela dos delitos de aptidão, defendida por Frisch. Para este autor, a punibilidade dos delitos de perigo abstrato estaria vinculada à afirmação ex ante da idoneidade do comportamento para conduzir a um resultado típico ${ }^{69}$.

4. Objeções à legitimidade de uma dogmática dos crimes de perigo abstrato

A dogmática dos delitos de perigo abstrato não goza, porém, de unanimidade na literatura jurídico-penal. Hassemer, ícone da escola de Frankfurt, rejeita a expansão do direito penal e, portanto, a antecipação de sua tutela. A proposta de um direito penal apenas nuclear e a transferência de questões como a dos delitos de perigo abstrato para uma terceira via denominada direito da intervenção é a melhor alternativa, consoante o autor ${ }^{70}$. Entre as objeções, destacam-se as abaixo elencadas.

\subsection{O princípio da culpabilidade}

A compatibilidade dos delitos de perigo abstrato com o princípio da culpabilidade é tida por muitos como duvidosa. Para Arthur Kaufmann, por exemplo, uma vez que o perigo não é elevado a elemento do tipo, mas apenas representa o motivo desconhecido do legislador, o delito é por exceção, então, realizado, mesmo se o perigo, presumido legalmente, em concreto absolutamente não existir. Isto tem como consequência o fato de que o autor não tem qualquer vantagem se ele, com ou sem razão, admite que sua conduta é absolutamente não perigosa. Também a culpabilidade se torna não passível de refutação ou até mesmo ilusória e vazia ${ }^{71}$.

Se o princípio da culpabilidade exige uma responsabilidade penal subjetiva, consubstanciada na demonstração de que um fato pode ser imputado ao seu autor não somente a título de mera causalidade, é evidente que aquele resta violado pela interpretação dos delitos de perigo abstrato como delitos de presunção ou sem qualquer necessidade de vinculação a elementos do tipo (um resultado de perigo concreto ou uma lesão).

\footnotetext{
${ }^{69}$ FRISCH, Wolfgang. An den Grenzen des Strafrechts. In: Küper, Wilfred/Welp, Jürgen (Hrsg.). Beiträge zur Rechtswissenschaft. Festschrift für Walter Stree/Johannes Wessels, 1993, p. 93

${ }^{70}$ HASSEMER, Winfried. Kennzeichen und Kreisen des moderenen Strafrechts. In: Zeitschrift für Rechtspolitik, 1992, p. 383.

${ }^{71}$ KAUFMANN, Arthur. Unrecht und Schuld beim Delikt der Volltrunkenheit. In: Juristenzeitung, 1963, p. 432.
} 
Os delitos de perigo abstrato, quando concebidos exclusivamente como presunção legislativa, prescindem de uma demonstração causal, calcando-se tão só em determinadas propriedades de uma ação, pelo que uma imputação passível de refutação no caso concreto seria bastante dificultosa. Neste sentido, a estrutura dos delitos de perigo abstrato assemelhase muito à de uma conduta culposa, só que sem o resultado lesivo. Por conseguinte, se o delito de perigo abstrato é classificado como delito de mera desobediência, viola-se o princípio da culpabilidade que pressupõe um injusto material.

\subsection{Objeções processuais e o in dúbio pro reo}

A perigosidade abstrata enquanto presunção do legislador revela incompatibilidades processuais, sobretudo, à luz da presunção de inocência e do in dubio pro reo.

Juarez Tavares assinala que uma estrutura democrática do injusto impõe que a presunção legal de perigosidade do comportamento possa ser submetida a uma refutação empírica, de modo que tais delitos fossem interpretados como crimes de perigo concreto. Com isto, o direito penal oferta a possibilidade, mais do que natural em um Estado de Direito, de o envolvido demonstrar a inocuidade do suposto perigo e ausência de sua responsabilidade penal $^{72}$.

A questão fundamental que se põe é a seguinte: dada a dificuldade de se provar a perigosidade ex ante da conduta, o que autorizaria ao Judiciário e ao Legislador optar pela presunção de perigo? Filosoficamente a ideia de um juízo de presunção só faz sentido como juízo provisório, suscetível à refutação. Do contrário, a presunção, em verdade, traduz-se em verdadeiro dever formal de abstenção.

Ainda no que tange ao âmbito processual, parece-nos que esta presunção legislativa é insuficiente para ativar a persecução criminal, de modo que cabe ao órgão acusador, sempre, a demonstração mínima de que as circunstâncias autorizadoras da afirmação de um perigo ex ante estavam presentes.

\subsection{O princípio da lesividade.}

A rigor, o princípio da lesividade é compreendido como uma verdadeira barreira à incriminação de qualquer conduta que não cause, ao menos, um perigo concreto para o bem

\footnotetext{
${ }^{72}$ TAVARES, Juarez. Teoria do Injusto Penal. 3.ed. Del Rey: Belo Horizonte, 2003, p. 226.
} 
jurídico. Esta ideia, contudo, apresenta alguns pontos discutíveis.

Em um primeiro olhar, eminentemente prático, adotar este conteúdo do princípio da lesividade culminaria na declaração de inconstitucionalidade de um sem-número de tipos penais atualmente vigentes, uma vez que muitas das condutas descritas não estariam abarcadas pela ideia, nada unânime, de perigo concreto ${ }^{73}$.

Conforme acentua Greco, este entendimento encerra um erro categorial, uma vez que a constitucionalidade ou não de certos tipos penais guarda pouca relação com a questão do bem jurídico $^{74}$. Assim, o tipo penal que proíbe o homicídio quer proteger o bem jurídico vida, assim como o tipo penal de incêndio, de perigo concreto, e o tipo penal que pró́be que as pessoas dirijam embriagadas (um tipo penal de perigo abstrato), também possuem por escopo a proteção da vida, ainda que em estágios diferentes de agressão. Isto quer dizer, consoante defende Hefendehl, que a questão em debate tem que ver com a "estrutura do delito" (Deliktstruktur $)^{75}$ ou “estrutura de proteção", e não com o objeto de proteção em si.

Em um plano mais fundamental, atrelado à teoria das normas, a postulação doutrinária que pretende fazer da existência do resultado (seja ele primário, no caso do perigo concreto, ou secundário, no caso da efetiva lesão) um pressuposto para a incriminação esbarra na constatação um tanto óbvia de que a norma jurídico-penal não pode proibir perigos concretos ou lesões, mas ela tão-só colima regulamentar condutas. Noutras palavras, conforme lição perene do finalismo: apenas as condutas humanas podem ser objeto da norma, mas não perigos ou lesões ${ }^{76}$.

Outra não é a intenção de um direito penal ao qual se incumbe a tarefa de proteger bens jurídicos. Conforme ressalta Binding a norma é apenas um meio, e não um fim em si mesmo nesta empreitada. Destarte, todas as proibições têm "apenas um e o mesmo fim: elas

\footnotetext{
73 Dentro desta linha de pensamento, crimes como a embriaguez na direção (art. 306 da Lei 9503/98); a participação em via pública de corrida, disputa ou competição automobilística que resulte em dano potencial à incolumidade pública (art. 308 da Lei 9503/98; o envenenamento de água potável ou de substância alimentícia ou medicinal (art. 270 do Código penal); a corrupção ou poluição de água potável (art. 271 do Código penal); a omissão de alerta aos consumidores quanto à nocividade ou periculosidade de produtos já colocados no mercado (art. 64 da Lei 8078/90) e muitos deveriam ser simplesmente declarados inconstitucionais ou ilegítimos por violação ao princípio da lesividade. A reflexão a ser feita é: poder-se-á advogar seriamente a extinção de tais tipos penais?

${ }^{74}$ GRECO, Luis. "Princípio da ofensividade" e crimes de perigo abstrato - Uma introdução ao debate sobre o bem jurídico e as estruturas de delito. In: Revista Brasileira de Ciências Criminais, São Paulo, Brasil, v.12, n.49, jul./ago. 2004.., p.119.

${ }^{75}$ HEFENDEHL, Roland. Kollektive Rechtsgüter im Strafrecht. Köln; Berlin; Bonn; München: Carl Heymanns Verlag KG, 2002, p. 182 et seq.

${ }^{76}$ Cf. KAUFMANN, Armin. Lebendiges und Totes in Bindings Normentheorie. Normlogik und modern Strafrechtsdogmatik. Göttingen: Otto Schwartz, 1954, pp. 71,102; KAUFMANN, Armin. Zum Stande der Lehre vom personalen Unrecht. In: STRATENWERTH, Günter. (Ed.). Festschrift für Hans Welzel, Berlin/New York: Walter de Gruyter, 1974, p.153
} 
querem impedir que, através de determinadas ações humanas, certas modificações sejam causadas no mundo do direito" 77 .

\section{Considerações Finais}

\subsection{Apreciação das críticas}

Expostas as principais contribuições sobre o tema, faz-se imperioso ofertar ao leitor a orientação que o estudo considera mais acertada, bem como as razões necessárias e suficientes para tal.

Em primeiro lugar, não parece, pelas razões expostas no tópico anterior, que seja possível recusar os delitos de perigo abstrato enquanto estrutura de proteção legítima a bens jurídicos, não raro, considerados vitais. O fundamento dos chamados delitos de perigo abstrato, contudo, não se encontra em uma teoria da presunção e tampouco exclusivamente no bojo uma teoria de proteção a bens jurídicos.

Naturalmente, a proteção de bens jurídicos realizada pelo direito penal não pode ser ilimitada. É justamente em virtude do caráter consequencialista da proteção a bens jurídicos que este estudo considera que o critério apto a distinguir o que pode ou não ser criminalizado não se extrai desta teoria. A teoria de proteção a bens jurídicos, assim como qualquer outra teoria de proteção, padece de um problema central que se desdobra em muitos outros: o problema do caráter consequencialista ${ }^{78}$, que é ínsito à ideia de proteção. Essa natureza é evidenciada por dois aspectos: um diz com a essência da ideia de proteção, o outro com o método utilizado pela teoria de proteção a bens jurídicos.

Em primeiro lugar a ideia de proteção, em seu sentido negativo, significa o reconhecimento de certos bens como valiosos e dignos de preservação. Isto é o que a norma quer proteger. $\mathrm{O}$ sentido positivo, por seu turno, evidencia a necessidade de um fazer dirigido para o futuro. Evidencia, portanto, um dever ou uma função atribuída à norma no sentido de dar máxima efetividade à esta proteção. Pergunta-se aqui não só a respeito "dos bens que a norma quer proteger", mas, sobretudo, pergunta-se "o que é preciso fazer para garantir de

\footnotetext{
${ }^{77}$ BINDING, Karl. Die Normen und ihre Übertretung. Eine Untersuchung über die rechtmäßige Handlung und ihren Arten des Delikts. 4.Auflage. Leipzig: Weidmann, 1922, p. 325. No trecho original: “...nun haben alle Verbote, wie früher schon gezeigt ist, nur einen und denselben Endzweck: sie wollen verhüten, dass durch menschliche Handlungen gewisse Veränderungen in der Rechtswelt herbeigeführt werden".

${ }^{78}$ Neste sentido, decisivamente: GRECO, Luis. Was lässt das Bundesverfassungsgericht von der Rechtsgutslehre übrig? Gedanken anlässlich der Inzestentscheidung des Bundesverfassungsgerichts. In: Zeitschrift für Internationale Strafrechtsdogmatik (ZIS), 2008, p. 234 et seq.
} 
modo efetivo a incolumidade desses bens".

Ao incumbir o direito penal da tarefa de proteger certas situações, a teoria de proteção a bens jurídicos materializa seu sentido positivo e, portanto, consequencialista: uma orientação dirigida às consequências, aos aspectos futuros de uma ação. E, deste modo, o primeiro aspecto encontra o segundo, pois quando se utiliza do método estipulado pela teoria do bem jurídico, através da proposição (p) "uma conduta só pode ser criminalizada ou considerada um crime se ela afeta bens jurídicos", se está na verdade afirmando que "as consequências de uma conduta só podem torná-la criminosa se afetarem um bem jurídico". Muito embora parte da compreensão dessa proposição tenha que ver com aquilo que se entende por bem jurídico, esta é uma observação não tão importante quanto o fato de que em praticamente todo comportamento humano é possível vislumbrar uma consequência potencialmente indesejável e perigosa a um bem jurídico. E, em se admitindo que o importante é evitar a afetação do bem jurídico, deduz-se que esta proteção deve ter máxima efetividade possível, o que a torna potencialmente sem limites na consecução de tal desiderato.

Por este motivo, este estudo não concebe a ideia de proteção a bens jurídicos como condição suficiente para legitimar o delito de perigo abstrato. Posto isto, como, então, vislumbrar um critério apto a distinguir delitos de perigo abstrato legítimos e ilegítimos?

\section{$5.2 \mathrm{O}$ fundamento}

Conforme defende este estudo, o critério mais promissor e determinante para separar as condutas criminalizáveis daquelas não criminalizáveis é o apelo a uma teoria da autonomia $^{79}$. Como proposta ainda em desenvolvimento, este trabalho não pretende fornecer um delineamento pronto e acabado de tal esfera, mas tão-só orientações mais ou menos gerais e suas repercussões mais importantes para o tema.

A noção de esfera imponderável de autonomia consiste no conjunto universal, igual e graduável de possibilidades de realização de valores do sujeito no âmbito privado ${ }^{80}$. Isto é, as possibilidades de exercício da liberdade que se materializam como doação de sentidos do

\footnotetext{
79 Esta proposta foi feita por: GRECO, Luis. Strafbarer Drogenbesitz, Privatsphäre, Autonomie: Überlegungen anlässlich der Entscheidung des argentinischen Verfassungsgerichts zur Verfassungswidrigkeit des Straftatbestandes des Besitzes von Betäubungsmitteln zum Zwecke des Eigenkonsums. In: HEFENDEHL, Roland (Ed). Grenzenlose Vorverlagerung des Strafrechts? Berlin: BWV, Berliner Wiss. Verlag, 2010, pp. 73-88.

${ }^{80}$ As características da universabilidade, da igualdade e a do caráter graduável são também expostas no artigo citado na nota anterior.
} 
sujeito para a sua própria existência. Toda e qualquer proibição deve observar este limite, sob pena de perder sua razão de ser. Pois, se a norma é fruto da escolha, percepção ou intuição de valores, processo este fundado na consciência e na liberdade (o valor que permite a realização de todos os demais), é preciso reconhecer aos sujeitos uma esfera imponderável de agir, por mais que tais doações de sentido no âmbito existencial privado sejam consideradas imorais, reprováveis por distintos segmentos sociais ${ }^{81}$.

A esfera de autonomia é universal, pois evidentemente pertence e é nota característica de todos os sujeitos. É igual, na medida em que não constitui privilégio de alguns em detrimento de outros e graduável, uma vez que embora todos sujeitos sejam dignos de respeito, há de se observar diferenças na capacidade e possibilidade de exercício dessa esfera.

Além disto, como nota essencial, ela é imponderável, o que significa dizer: não pode servir como ponto a ser ponderado para que se atinja determinado fim, isto é, situa-se no campo daquilo que é inegociável. A esfera de autonomia significa este conjunto de possibilidades de relação que dizem respeito a um projeto existencial do sujeito. Significa, ademais, a margem de arbítrio tolerável e insuscetível de ponderação que cabe a cada um dos sujeitos.

Este limite condicionante não constitui, como dissemos, uma teoria pronta e acabada, e, tampouco, é objetivo deste trabalho oferecer um retrato perfeito e pleno dessa esfera. É, porém, um de seus objetivos sublinhar o fato de que a esfera de autonomia tem papel crucial condicionante de uma teoria de proteção a bens jurídicos.

Mas como exatamente a esfera de autonomia releva para os delitos de perigo abstrato? $\mathrm{Na}$ medida em que uma teoria da esfera imponderável de autonomia fixa o que pertence a este núcleo e, portanto, impede o processo criminalizante do Estado, ela fixa também o que está fora deste núcleo e pode, caso necessário seja, ser criminalizado.

\footnotetext{
${ }^{81}$ A esfera imponderável de autonomia aqui proposta difere, contudo, daquela proposta por Greco na medida em que se funda no apriorismo da consciência do sujeito à luz da fenomenologia de Edmund Husserl. A esfera de autonomia incorpora, assim, uma relação de intencionalidade que o sujeito estabelece no mundo como projeção de seu projeto existencial. A consciência, aqui, é tomada conforme uma concepção husserliana. Ou seja, toda a consciência é consciência de algo ("Bewusstsein von etwas zu sein"). A consciência é compreendida como o fundamento último da liberdade, como um dos elementos centrais para a própria ideia de sujeito. A consciência é o a priori que permite ao sujeito intuir valores. Tais valores, vistos como um reino autônomo de possibilidades são, por meio da intencionalidade essencial à consciência, percebidos pelo sujeito. Nas palavras de Husserl, "a propriedade fundamental do modo da consciência, na qual 'eu' vivo como 'Eu', é a chamada intencionalidade, é ter a respectiva consciência de algo”. Uma vez que estes valores são percebidos pelo sujeito, que é dotado de liberdade (condição de realizabilidade de todos outros valores), eles adquirem concretude ou materialização no mundo da vida enquanto possibilidades fáticas de relações que este sujeito. Sobre o fundamento e natureza da consciência: HUSSERL, Edmund. Cartesianische Meditationen und Pariser Vorträge. Netherlands: Kluwer Academic Publischens, 1991, p.13. Trecho original citado:" Die Grundeigenschaft der Bewußtseinsweisen, in denen 'ich' als 'Ich' lebe, ist die sogenannte Intentionalität, ist jeweiliges Bewußthaben von etwas”.
} 
Conforme defende este estudo, a determinação do que pertence ou não à esfera de autonomia se dá através do princípio da responsabilidade, sobretudo em sua natureza interrelacional. Naturalmente, faz-se improvável a imposição de um critério universal em função não apenas das complexidades inerentes ao meio social, bem como em virtude da historicidade e temporalidade do Direito. É possível, contudo, fixar algumas hipóteses esclarecedoras acerca do manejo do princípio da responsabilidade interrelacional. A princípio, duas situações podem ser aduzidas.

Em primeiro lugar, o campo da autonomia interna. Este campo consiste nas condutas praticadas pelo sujeito e que dizem respeito direta e intencionalmente à sua pessoa, mas que podem vir a gerar consequências diretas ou indiretas, comprometedoras ou não, em relação aos bens ou ao exercício dos outros.

Em segundo lugar, o âmbito da autonomia externa. Este diz respeito às condutas praticadas pelo sujeito e que dizem respeito direta e intencionalmente ao outro ou ao meio, e que podem vir a gerar consequências imediatas ou mediatas, comprometedoras ou não, em relação aos bens ou à esfera de terceiros ou em relação ás condições do meio ou ambiente em que estão situados os sujeitos. Condições estas que sustentam a cooperação voluntária dos sujeitos e é essencial à coexistência.

O fato de determinada hipótese pertencer ao plano da autonomia interna ou externa não faz dela, desde logo, criminalizável ou não. A divisão tem um teor eminentemente didático, a fim de melhor precisar o tipo de relação que se estabelece. Assim, um indivíduo que adquira a obra Mein Kampf pode ou não tornar-se um adepto do nazismo no futuro, mas o mero fato de ele ter ou ler a obra parece não admitir criminalização, uma vez que se situa no âmbito de sua projeção existencial como esfera imponderável de autonomia. Já uma manifestação nazista nas proximidades de um bairro reconhecidamente de judeus não parece justificável como expressão da esfera imponderável da autonomia materializável no direito à liberdade de expressão.

Ainda que distante de um tratamento exaustivo, parece-nos que a esfera imponderável de autonomia junto ao sub-critério da responsabilidade interrelacional deve lidar com três critérios: a) o grau de imediatidade entre a conduta e as consequências lesivas ou arriscadas desta conduta para bens jurídicos alheios; b) o grau de comprometimento que a conduta pode gerar para os bens jurídicos de terceiros; c) o grau de imprescindibilidade do bem jurídico protegido de terceiros e d) o limite da relevância do consentimento.

Desta feita, enquanto conclusão intermediária e merecedora de ulteriores investigações, o presente estudo se orienta no sentido de fundamentar os delitos de perigo 
abstrato através do princípio da responsabilidade interrelacional, responsável também, em grande medida, por separar o que pertence ou não ao núcleo imponderável de autonomia.

5.3 A natureza dos delitos de perigo abstrato

Uma vez esclarecia a base fundamental que legitima a possibilidade jurídica dos crimes de delito abstrato, passa a fazer sentido entendê-los, dogmaticamente, enquanto estrutura de proteção em referência a um objeto de proteção: o bem jurídico. Segundo defende este estudo, um ponto em comum, ainda que bastante geral, quanto às diversas formas de aparição dos delitos de perigo abstrato pode ser encontrado, assim, na diminuição ou violação da possibilidade de o sujeito estabelecer uma relação de disposição com um determinado objeto reconhecido pelo direito como valoroso. Consoante se defende também nesta sede, o bem jurídico não é um objeto, mas a possibilidade empiricamente vulnerável e reconhecida pelo direito de um sujeito, submetido a um estado inescapável de coexistência, estabelecer uma relação ${ }^{82}$ respeitosa no mundo, isto é, com os objetos a este inerente.

No que diz respeito à estrutura dos delitos de perigo abstrato, a alternativa mais promissora parece a de continuar o trabalho de distinção entre grupos de crimes mais ou menos similares entre si. Com o auxílio de argumentos providos pela aplicação do princípio da responsabilidade interrelacional é possível vislumbrar os tipos de estrutura comprometidos em evitar as diferentes formas e graus de afetação do bem jurídico.

\section{Referências Bibliográficas}

BERZ, Ulrich. Formelle Tatbestandsverwirklichung und materialer Rechtsgüterschutz. Eine Untersuchung zu den Gefährdungs- und Unternehmensdelikten. München, 1986 BINDING, Karl. Die Normen und ihre Übertretung. Eine Untersuchung über die rechtmäßige Handlung und ihren Arten des Delikts. 4.Auflage. Leipzig: Weidmann, 1922.

\footnotetext{
${ }^{82}$ Peter Sina e Zaffaroni, em termos semelhantes, também concebem o bem jurídico como uma relação e uma relação de disponibilidade, respectivamente, entre um sujeito e determinado objeto. Cf. SINA, Peter.

Dogmengeschichte des strafrechtlichen Begriffs "Rechtsguts". Helbing \& Lichtenhalten: Basel, 1962, p. 101; ZAFFARONI, E.R. Derecho penal: parte general. 2.ed. Buenos Aires: ediar, 2002, p. 489 et seq.
} 
BREHM, Wolfgang. Zur Dogmatik des abstrakten Gefährdungsdelikts. Dissertation Tübingen, 1973

CRAMER, Peter.Vollrauschtatbestand als abstraktes Gefährdungsdelikt. Tübingen : J.C.B. Mohr (Paul Siebeck), 1962.

FRISCH, Wolfgang. An den Grenzen des Strafrechts. In: Küper, Wilfred/Welp, Jürgen (Hrsg.). Beiträge zur Rechtswissenschaft. Festschrift für Walter Stree/Johannes Wessels, 1993, pp. 69-106.

KAUFMANN, Arthur. Unrecht und Schuld beim Delikt der Volltrunkenheit. In: Juristenzeitung, 1963, pp. 425-432.

KAUFMANN, Armin. Lebendiges und Totes in Bindings Normentheorie. Normlogik und modern Strafrechtsdogmatik. Göttingen: Otto Schwartz, 1954

Zum Stande der Lehre vom personalen Unrecht. In: STRATENWERTH, Günter. (Ed.). Festschrift für Hans Welzel, Berlin/New York: Walter de Gruyter, 1974, pp. 393-414

KUHLEN, Lothar. Der Handlungserfolg der strafbaren Gewässerverunreinigung (§ 324StGB). In: Goltdammer's Archiv für Strafrecht, 1986, p. 389 et seq.

Umweltstrafrecht - auf der Suche nach einer neuen Dogmatik. In:

Zeitschrift für die gesamte Strafrechtswissenschaft, 105, 1993, pp. 697-726.

GRECO, Luis. Strafbarer Drogenbesitz, Privatsphäre, Autonomie: Überlegungen anlässlich der Entscheidung des argentinischen Verfassungsgerichts zur Verfassungswidrigkeit des Straftatbestandes des Besitzes von Betäubungsmitteln zum Zwecke des Eigenkonsums. In: HEFENDEHL, Roland (Ed). Grenzenlose Vorverlagerung des Strafrechts? Berlin: BWV, Berliner Wiss. Verlag, 2010, pp. 73-88

. Was lässt das Bundesverfassungsgericht von der Rechtsgutslehre übrig? Gedanken anlässlich der Inzestentscheidung des Bundesverfassungsgerichts. In: Zeitschrift für Internationale Strafrechtsdogmatik (ZIS), 2008,pp. 234-238.

. "Princípio da ofensividade" e crimes de perigo abstrato - Uma introdução ao debate sobre o bem jurídico e as estruturas de delito. In: Revista Brasileira de Ciências Criminais, São Paulo, Brasil, v.12, n.49, jul./ago. 2004, pp. 89-147.

HASSEMER, Winfried. Kennzeichen und Kreisen des moderenen Strafrechts. In: Zeitschrift für Rechtspolitik, 1992, pp. 378-383

HEFENDEHL, Roland. Kollektive Rechtsgüter im Strafrecht. Köln; Berlin; Bonn; München: Carl Heymanns Verlag KG, 2002. 
HIRSCH, Hans-Joachim. Gefahr und Gefährlichkeit, in: Strafgerechtigkeit. Festschrift fürArthur Kaufmann, 1993, pp. 545-563.

HORN. Eckhard. Konkrete Gefährdungsdelikte. Köln: Schmidt, 1973

HOYER, Andreas. Die Eignungsdelikte. Duncker \& Humboldt: Berlin, 1987

HUSSERL, Edmund. Cartesianische Meditationen und Pariser Vorträge. Netherlands:

Kluwer Academic Publischens, 1991

KINDHÄUSER, Urs. Gefährdung als Straftat: rechtstheoretische Untersuchungen zur Dogmatik der abstrakten und konkreten Gefährdungsdelikte. Klostermann: Frankfurt am Main, 1985

MAURACH, Reinhart; ZIPF, Heinz. Strafrecht Allgemeiner Teil. 8.Auflage. München: Beck, 1992

OTTO, Harro. Grundkurs Strafrecht. Allgemeine Strafrechtslehre. 7.Auflage. Berlin: Walter de Gruyter, 2004

ROXIN, Claus. Strafrecht. Allgemeiner Teil. 4.Auflage. München: C.H. Beck, 2006

SCHRÖDER, Horst. Die Gefährdungsdelikte im Strafrecht. In: Zeitschrift für die gesamte Strafrechtswissenschaft, 81 (1969), p. 16 et seq.

SCHÜNEMANN, Bernd. Moderner Tendenzen in der Dogmatik der Fahrlässigkeits- und Gefährdungsdelikte. In: Juristische Arbeitsblätter, 1975, p. 793 et seq

SILVA DIAS, Augusto. "What if everybody did it?": sobre a (in)capacidade de ressonância do Direito Penal à figura da acumulação. In: RPCC, ano 13, 2003, p. 311 et seq.

TAVARES, Juarez. Teoria do Injusto Penal. 3.ed. Del Rey: Belo Horizonte, 2003

VOLZ, Manfred. Unrecht und Schuld abstrakter Gefährdungsdelikte. Dissertation Göttingen, 1968

WESSELS, Johannes; BEULKE, Werner. Strafrecht Allgemeiner Teil. Die Straftat und ihr Aufbau. 32.ed. CF Müller verlag: Heidelberg, 2009

WOLTER, Jürgen. Objektive und personale Zurechnung von Verhalten. Gefahr und Verletzung in einem funktionalen Straftatsystem. Berlin, 1981

Imputación objetiva y personal a titulo de injusto. A la vez, una contribución al estúdio de la aberratio ictus. In: (Hrsg.) SCHÜNEMANN, Bernd. El sistema moderno del Derecho penal: cuestiones fundamentals. Madrid: tecnos, 1991, p. 108 et seq.

WOHLERS, Wolfgang. Teoria del bien jurídico y estructura del delito. Sobre los criterios de una imputación justa. Traduzido do original: Rechtsgutstheorie und Deliktsstruktur - zu den Kriterien fairer Zurechnung. In: HEFENDEHL, Roland (ed). La teoria del bien juridico. 
Fundamento de legitimación del derecho penal o juego de abalorios dogmático? Marcial Pons: Madrid, 2006.

Deliktstypen des Präventionsstrafrechts - zur Dogmatik „moderner” Gefährdungsdelikte. Berlin: Dunckler und Humblot, 2000 